\title{
HYDROTHERMALLY-CALCINED WASTE PAPER ASH NANOMATERIAL AS AN ALTERNATIVE TO CEMENT FOR CLAY SOIL MODIFICATION FOR BUILDING PURPOSES
}

\author{
Ubong Williams Robert ${ }^{a}$, Sunday Edet EtuK ${ }^{b}$, \\ Okechukwu Ebuka Agbasi ${ }^{c, *}$, Grace Peter Umoren ${ }^{a}$, \\ Samuel Sunday AKran ${ }^{a}, \operatorname{Lebe}^{*}$ Agwu Nnanna ${ }^{c}$ \\ ${ }^{a}$ Akwa Ibom State University, Faculty of Physical Sciences, Department of Physics, P.M.B. 1167, Ikot Akpaden, \\ Mkpat Enin, Akwa Ibom State, Nigeria \\ ${ }^{b}$ University of Uyo, Faculty of Science, Department of Physics, P.M.B. 1017, Uyo, Akwa Ibom State, Nigeria \\ ${ }^{c}$ Michael Okpara University of Agriculture, College of Physical Science, Department of Physics, P.M.B. 7267, \\ Umudike, Abia State, Nigeria \\ * corresponding author: agbasi.okechukwu@gmail.com
}

\begin{abstract}
It has been observed that clay soil cannot be used for building design, unless it is modified by firing or with cement. Either method of stabilization can adversely affect the environment and public health just like indiscriminate dumping or open burning adopted in developing countries as the prevalent disposal technique for waste papers. This paper sought to examine the feasibility of using assorted waste papers to derive an alternative stabilizer to Portland Limestone Cement for modification of clay soil into composite materials suitable for building design. Specifically, clay-based composites were fabricated at $0 \%, 5 \%, 10 \%, 15 \%$, and $20 \%$ replacement levels by weight with cement, and then hydrothermally-calcined waste paper ash nanomaterial (HCWPAN). Water absorption, sorptivity, bulk density, thermal conductivity, specific heat capacity, thermal diffusivity, flaking concentration, flexural strength, and compressive strength were investigated for each of the fabricated samples. Irrespective of the stabilizing agent utilized, $10 \%$ loading level was found to be the optimum for possession of maximum mechanical strength by the samples. Only samples with the HCWPAN content were found to be capable of reducing building dead loads and improving thermal insulation efficiency over un-stabilized clay material, if applied as walling elements in buildings. Generally, it was revealed that the cement and HCWPAN have comparable influences on the properties of clay soil, thus indicating that HCWPAN could be utilized as an alternative stabilizer to cement. In addition, the preparation of HCWPAN was found to be more energy-saving than that of the cement.
\end{abstract}

KEYWORDS: Bulk density, building design, compressive strength, sorptivity, thermal conductivity.

\section{INTRODUCTION}

In recent decades, the impacts of technology on society have been pronounced, especially, in terms of changes in relation to survival needs such as foods and shelter as well as aspirations among which is knowledge. Being a powerful tool in the development of civilization, technology may be regarded as a complex social enterprise that includes design, manufacturing, research, management, finance, marketing, etc. With that, it suffices to assert that technology and human life cannot be separated. This is because as long as there have been people, there has been technology. The utilization of natural resources like clay as a building material is one chief evidence showing that the society has a cyclical dependence on technology. Traditionally, clay is used in the form of bricks, plasters or mortars for shelter construction. As posited by Bredenoord 1], homes made with clay bricks have a better moisture regulation and are more comfortable than those built with hollow concrete blocks. From an environmental standpoint, this is a pointer to the fact that the application of clay bricks as walling elements in buildings can reduce the impact of natural resource consumption.

Through technological innovation, the strength and durability properties of clay bricks can be improved. One way of achieving such an improvement is by thermal treatment, a technique which involves firing clay bricks at high temperatures in a kiln [2 4]. Another effective method of clay modification is chemical treatment using Portland cement [5-7]. However, the said methods portend great dangers. In the case of thermal treatment, for instance, wood is used to fuel the kilns and this practice leads to deforestation, in addition to a large scale emission of carbon dioxide, among other things. Also, it is possible to produce uneven bricks as those closest to the heat source may be over-dried. Similarly, cement production involves high energy usage followed by an emission of a large amount of carbon dioxide capable of causing serious environmental problems. As observed by several researchers including Chen et al. [8], Zhang et al. [9], and 
Shen et al. 10, cement industry accounts for 5-7\% of the global anthropogenic carbon dioxide. Though the amount emitted depends on the kiln type, clinker to cement ratio, fuel used, efficiency of energy utilization as well as the demand for cement, it is well-known that global warming is a serious threat, which our planet is facing daily and carbon dioxide is a vital factor in it.

Some other studies have revealed that clay can be chemically modified using ashes derived from solid plant-based agro-wastes like sugarcane bagasse [11, 12, rice husk [13 15], corn cob [16], groundnut shell [17, palm oil fuel and palm kernel shell [18. In all these reported cases, the stabilizing agents exhibit good properties compared to cement in terms of improvement in the properties of the resulting clay-based composites. That notwithstanding, their utilization for the stabilization of clay is associated with major drawbacks. Observably, agro-wastes used in preparing ashes are generated after harvesting. As such, since harvesting depends on maturity and economic issues/demand in relation to individual crops, the availability of the wastes in question may be negatively affected by seasonal influence on crops. Moreover, several researchers have also reported that fly ash and slag [19 23], nano iron oxide 24], nano aluminium [25], nano silica [26, 27], nano magnesium oxide [28] are useful stabilizers for the improvement of mechanical and resistance properties of clay.

It has been observed that our society lies in $3 \mathrm{E}$ (Energy, Economy, and Environment) and while the society needs to keep all energy options open to satisfy the growing demand, the economy of a country directly relies on the transformation and utilization of resources. In this regard, there is a need to recycle a readily available waste in order to ensure a sustainable building construction. A typical waste that fits into the sustainability context is unused paper. Paper is simply a cellulose-based material that is used daily for a number of different applications (such as packaging, writing, drawing, books, industrial purposes, etc). World Facts Report in 2017 has shown that 215,125,083 tons of paper are produced by 10 countries worldwide. This agrees with the report of O'mara [29] that 300 million tons of paper are produced yearly throughout the world. Being a necessity of civilization, there can be no halt in the production of paper.

Like in other cases, the technological revolution with respect to paper manufacturing also has negative impacts on the society. Paper considered to be of no further use is usually treated as a waste material. McKinney 30 noted that papers and paper products constitute approximately $25-40 \%$ of globally generated solid wastes. In developing countries like Nigeria, solid waste management is ineffective, thus leading to open burning as a prevalent way of getting rid of waste paper materials. This practice has the potential to increase the carbon footprint in the environment. According to a February 2020 report released by the International Energy Agency, the global energy-related carbon dioxide emission plateaued in 2019 at $33 \mathrm{Gt}$. Though waste paper and its ashes are found to be useful for the production of thermal insulation panel products/ceilings [31-36] and preparation of concrete 37,38 as well, there is a need to further devise a scientifically-safe way of minimizing the huge quantity of such waste materials for beneficial purpose(s). Hence, by carefully considering the aforementioned situations in the light of a sustainable building design, this study is designed to assess the feasibility of utilizing hydrothermally-calcined waste paper ash nanomaterial (HCWPAN) as an alternative stabilizer to cement for clay modification for building purposes. Specifically, a comparison will be made between the use of HCWPAN and cement in terms of thermophysical and strength properties of the resulting clay-based composites and also the energy involvement in the production processes.

\section{EXPERIMENTAL PERSPECTIVE}

\subsection{Materials COLleCtion AND DESCRIPTION}

Portland Limestone Cement (CEM II B-L 32.5R), pink clay soil, and assorted waste papers were the main materials utilized in this study. The clay soil, as collected, was wet and plastic in nature. All the materials were gathered in large quantities within Uyo metropolis in Akwa Ibom State, Nigeria.

\subsection{Processing of the Clay and PREPARATION OF THE HCWPAN}

The clay soil was sun-dried to a constant weight and then crushed by means of hammer. Using a $2 \mathrm{~mm}$ sieve, the crushed soil material was screened and the quantity of it that passed through the openings was used in this work. Also, the surfaces of the waste papers were cleaned before the papers were shredded with the aid of a pair of scissors. By means of an incinerator (Model i8-20S), the paper pieces were burnt to ash for 1 hour at $850{ }^{\circ} \mathrm{C}$. This type of incinerator is capable of operating without odours, smoke, or harmful emissions. After that, the ash was sieved to remove any accompanying impurity and also to obtain fraction size passing through $250 \mu \mathrm{m}$ openings. Then, two stages of heat treatment were adopted to prepare the HCWPAN, thus:

A mixture of the sieved ash and tap water was stirred for 0.5 hour using magnetic stirrer and then heated for 12 hours in a Teflon-lined autoclave at $200^{\circ} \mathrm{C}$. Using an electric furnace, the preheated cursor was calcined at $750{ }^{\circ} \mathrm{C}$ for 4 hours and after cooling to $35^{\circ} \mathrm{C}$, it was pulverized in an Agate mortar and then ball-milled by means of a high-energy ball milling machine $\left(\mathrm{E}_{\max }\right.$, manufactured by RETSCH GmbH) at $500 \mathrm{rpm}$ for 6 hours. This ball miller is capable of ensuring a reduction in the particle sizes of a material 


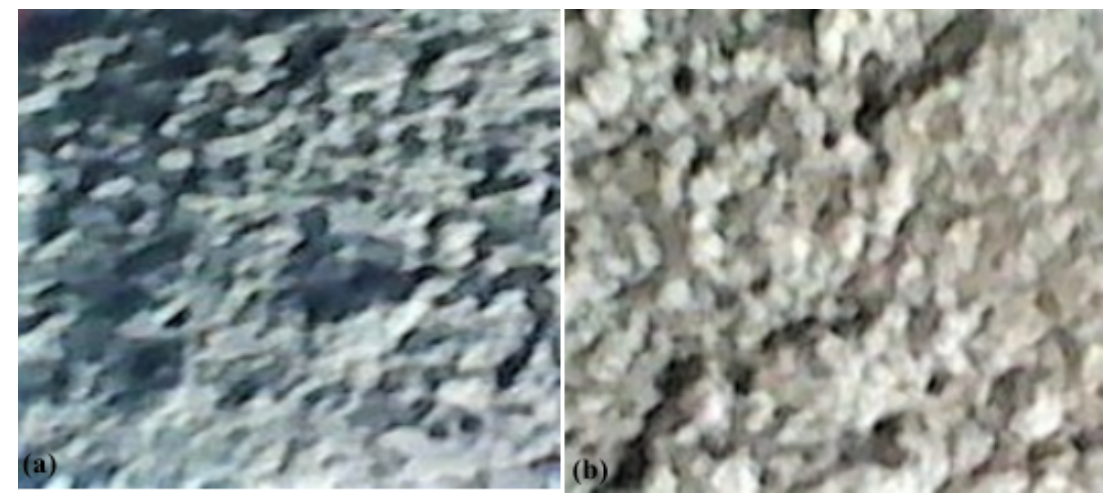

Figure 1. Used forms of the (a) Cement (b) HCWPAN.

\begin{tabular}{lccccc}
\hline Weight fraction of clay soil (\%) & 100 & 95 & 90 & 85 & 80 \\
Weight fraction of the HCWPAN or Cement used (\%) & 0 & 5 & 10 & 15 & 20 \\
\hline
\end{tabular}

TABle 1. Proportioning of the sample mixes.

feed from about $5 \mathrm{~mm}$ to as fine as less than $80 \mathrm{~nm}$. The clay soil, cement, and HCWPAN used in this work are shown in Figure 1

\subsection{ANALYSIS OF THE MATERIALS}

The clay soil, cement, and HCWPAN were each divided into portions. Using one portion of each material, static angle of repose was determined by a fixed funnel method 39. Also, by employing a hydrometer method of sedimentation [40, the particle size analysis of the clay soil was performed after which the percentage passing was plotted against the particle diameters on a logarithmic scale. With the aid of X-ray fluorescence analyser (Spectro X-lab 2000), the chemical composition as well as the loss on ignition were determined for the materials as per the technique used by [1, 42.

\subsection{FABRICATION OF TEST SAMPLES}

Using the remaining portion of each material, various similar weight fractions of cement and HCWPAN were thoroughly and separately mixed with the clay soil as presented in Table 1 After moistening with water (ranging in a quantity from $23.8 \%$ to $34.1 \%$ by dry weight of the material mix), the resulting mixture was compacted with a load of $50 \mathrm{~kg}$ for 12 hours. Whereas test samples meant for the investigation of thermophysical properties were prepared to be $9.0 \mathrm{~mm}$ in thickness and $110 \mathrm{~mm}$ in diameter, those for the strength characterization were developed in a mould measuring $210 \times 36 \times 12 \mathrm{~mm}$. The samples were fabricated in triplicates per formulation. Prior to the conduction of the intended tests on each of them, the samples were oven-dried until they became moisturefree.

\subsection{Properties investigation}

Each sample developed for the assessment of thermophysical properties was first subjected to a thermal conductivity test using Modified Lee-Charlton's Disc Apparatus Technique [43. Then, the samples were carefully cut into sizes needed for water absorption, bulk density, sorptivity, and specific heat capacity tests. The method used by Shrestha [4] was adopted for the evaluation of water absorption, $W A$ of each sample. By means of a digital balance (S. METTLER $-600 \mathrm{~g}$ ), the mass of each sample was measured and their bulk volume was found by using Modified water displacement method [45. From the data obtained, the corresponding bulk density, $\rho$, was determined as

$$
\rho=\frac{M}{V},
$$

where $M=$ mass, and $V=$ bulk volume of the sample.

The shape of samples for the sorptivity test was made rectangular. Following the method used in previous work [46], with slight modifications, a sample was suspended from a digital scale by means of a strong and light inextensible string. After that, the reading on the scale was noted and the area of the sample's lower surface was determined. Also, a glass vessel containing water - saturated foam was placed directly under the sample. Then, the position of the sample was adjusted until its lower end rested on the foam (as illustrated in Figure 2). At that instant, a digital stopwatch was turned on to measure the infiltration time of the water. After every minute, the reading shown on the scale was noted and the initial reading obtained was subtracted from it in order to know the mass of the water that ingressed into the sample. The temperature of the water at that moment was determined with the aid of a digital thermometer equipped with a type-K probe and the water density at that temperature was noted as provided in 47. When 50 minutes elapsed, the water infiltration depth 


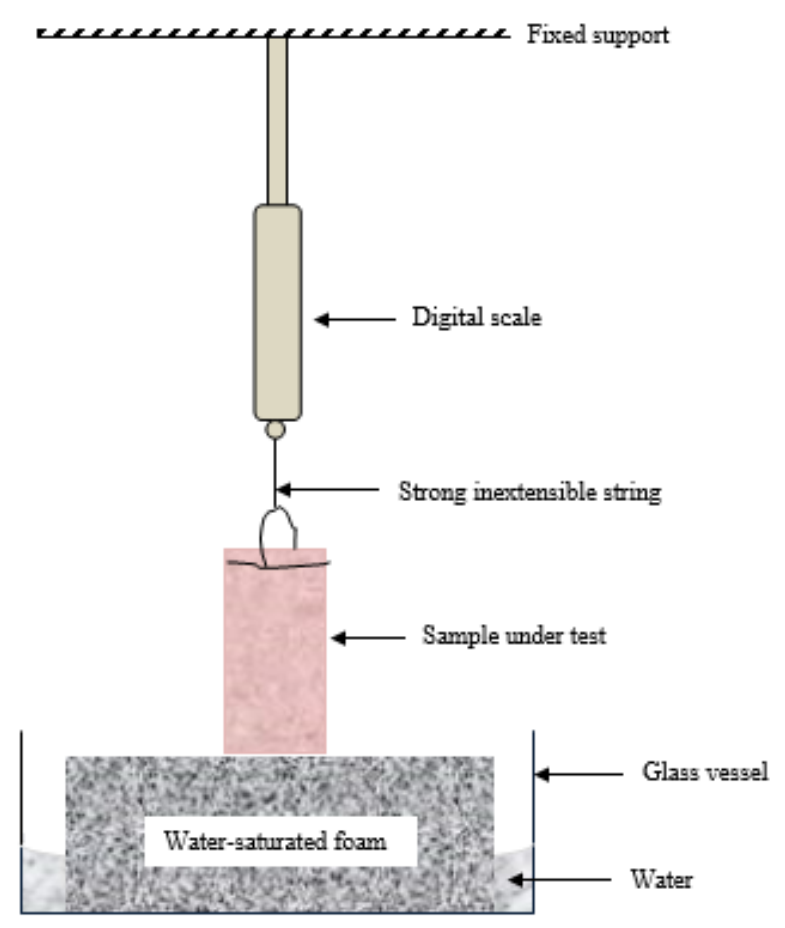

Figure 2. Schematic diagram for the sorptivity test.

at each interval of time was determined using the formula

$$
D=\left(\frac{W_{a}}{D_{w} a}\right),
$$

where $D=$ cumulative water infiltration depth, $W_{a}$ $=$ mass of water ingressed into the sample, $D_{w}=$ density of water, and $a=$ area of the sample's surface in contact with the foam.

The infiltration depth of the water was plotted against the square root of the time and the sorptivity value of the sample was deduced graphically based on the relation

$$
D=S_{p} \sqrt{t}
$$

where $S_{p}=$ sorptivity of the sample, and $t=$ infiltration time.

The measurement of specific heat capacity of each sample was carried out using SEUR'S Apparatus, as described elsewhere [48. In this case, other heat exchange accessories used were plates of aluminium and plywood (each having thickness of $10 \mathrm{~mm}$ ). The values of bulk density, thermal conductivity $(k)$, and specific heat capacity $(C)$ obtained for each sample were then applied to calculate the corresponding thermal diffusivity, $\lambda$ as

$$
\lambda=\frac{k}{\rho C} .
$$

The abrasion resistance was assessed by a flaking concentration test for each of the samples developed for the appraisal of strength. In this case, the initial mass of each test sample was measured after which a hard shoe brush was used to rub against their two surfaces until 70 strokes of forward and backward movements were made. For the purpose of ensuring that the pressure applied was uniform, a $0.5 \mathrm{~kg}$ weight was firmly attached to the top of the brush and the movement of the brush was activated by pushing and pulling it slowly over a sample under test. At the end of the process, the flaked samples were weighed and the percentage decrease in the mass of each tested sample was determined:

$$
F_{c}=\frac{\Delta M}{M_{o}} 100 \%,
$$

where $\Delta M=$ decrease in the mass of the sample after being flaked, and $M_{o}=$ mass of the sample before being flaked.

The flexural strength of the samples was determined by means of a computerised electromechanical universal testing machine (WDW-10) based on a three-point bending technique as stated in 49. During each test schedule, the sample under test was suspended as a single beam supported at two points and loaded at its mid-point until it fractured. With the data obtained, the value of flexural strength, $f_{s}$ was computed based on the relation:

$$
f_{s}=\frac{3 P L}{2 b x^{2}}
$$

where $P=$ maximum load applied at the fracture, $L=$ span length, and $b=$ width of the sample under test.

In the case of compressive strength, the values of crushing force, $F$, and cross-sectional area, $A$, of each sample were used for computation as 50

$$
C S=\frac{F}{A}
$$

All the tests were performed at room temperature with $\pm 2{ }^{\circ} \mathrm{C}$ variations. For each test, the mean and standard error values of the results obtained were tabulated.

\section{Results And Discussion}

The index properties of the clay soil, HCWPAN, and cement utilized in fabricating the samples are presented in Table 2 There is a slight difference in terms of static angles of repose of HCWPAN and cement, both of which are greater than the value obtained for the clay soil by about $40.8 \%$ and $35.4 \%$ respectively. Since the angle of repose is inversely proportional to the particle size of a material [51,52, it can be claimed that the clay soil contains particles that are the largest in size and those in the cement are larger as compared 


\begin{tabular}{lccc}
\hline \multirow{2}{*}{ Particulars } & \multicolumn{3}{c}{ Materials } \\
\cline { 2 - 4 } & Clay soil & HCWPAN & Cement \\
\hline Used form & Dry & Dry/powdery & Dry/powdery \\
Static angle of repose & $(29.4 \pm 0.1)^{\circ}$ & $(41.4 \pm 0.3)^{\circ}$ & $(39.8 \pm 0.1)^{\circ}$ \\
Plasticity index & $23.4 \%$ & - & - \\
\hline
\end{tabular}

TABle 2. Description of the materials used.

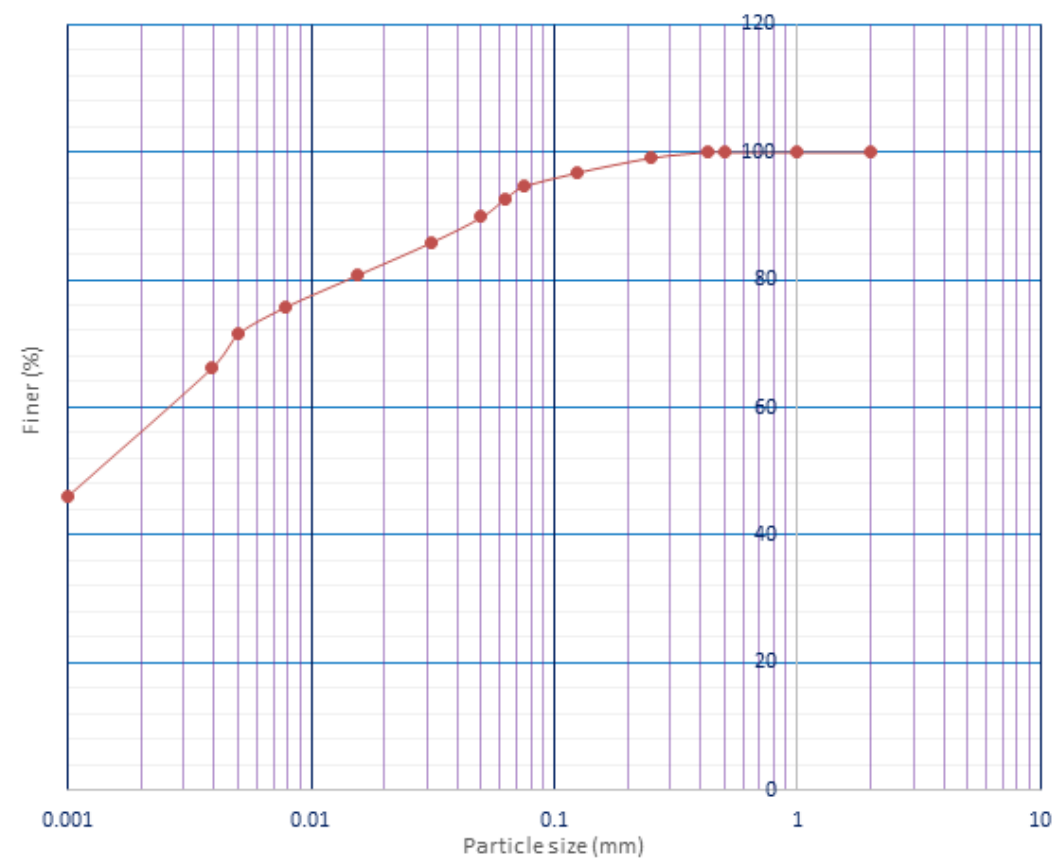

FiguRE 3. Particle size distribution of the clay soil used.

to the size of the particles in the HCWPAN. From Figure 3 , it can be observed that the clay-sized particles $(<2 \mu \mathrm{m})$ are more than silt particles $(0.06 \mathrm{~mm}-2 \mu \mathrm{m})$ while sand particles $(2 \mathrm{~mm}-0.06 \mathrm{~mm})$ constitute the least fraction. Also, by having nano-sized particles, HCWPAN is finer than cement and its fineness is typical enough to enable it to function as a binder as well as filler in the clay matrix to form a clay-based composite. Based on the interpretation that an angle of repose of $25^{\circ}$ to $30^{\circ}$ is for excellent flowability, whereas a value in the range of $41^{\circ}$ to $45^{\circ}$ indicates a passable flow property [53, it can be adjudged that the materials utilized in this study possess acceptable flow characteristics for manufacturing purposes.

Table 3 shows the chemical compositions of the clay soil, HCWPAN, and cement. Among the main oxides in the clay soil, $\mathrm{SiO}_{2}$ is of the highest proportion followed by $\mathrm{Al}_{2} \mathrm{O}_{3}, \mathrm{Fe}_{2} \mathrm{O}_{3}$, and then $\mathrm{CaO}$. It is noteworthy that while $\mathrm{CaO}$ manages the structure and rupture threshold of the soil, the alumina $\left(\mathrm{Al}_{2} \mathrm{O}_{3}\right)$ fraction promotes the increase in mechanical resistance. The percentage of silica $\left(\mathrm{SiO}_{2}\right)$ in the clay is approximately $50 \%$, thus agreeing well with the report of Velasco et al. [54] that clay used in bricks factories contains $50 \%$ to $60 \%$ of $\mathrm{SiO}_{2}$. This means that the clay soil used in this work is a suitable raw material for utilization in factories for brick making.

In the case of HCWPAN, the proportions of $\mathrm{SiO}_{2}$, $\mathrm{Al}_{2} \mathrm{O}_{3}$, and $\mathrm{Fe}_{2} \mathrm{O}_{3}$ sum up to $30.7 \%$. This value is less than $70 \%$ being the minimum requirement specified for a material to be a pozzolan [55], thus signifying that the HCWPAN cannot be regarded as a pozzolanic material in this case. However, the HCWPAN contains $\mathrm{CaO}(56.76 \%), \mathrm{SiO}_{2}$ (28.04), $\mathrm{Al}_{2} \mathrm{O}_{3}$ (1.61), and $\mathrm{MgO}(1.30)$ as the prominent constituents and the proportions of these oxides are similar in rankings to those in the cement used in this study. Also, the fraction of $\mathrm{CaO}$ in HCWPAN is very close to that of the cement. Chemical phases formed from the calcium, silicates, and aluminates contents of the admixtures in the cement are essential for strength development through hydration. Specifically, $\mathrm{SiO}_{2}$ aids in strength development. Also, in the presence of water, $\mathrm{CaO}$ first forms $\mathrm{Ca}(\mathrm{OH})_{2}$ and with the availability of carbon dioxide, yields $\mathrm{CaCO}_{3}$ for hardening and strength development. It is, therefore, obvious that the HCWPAN is cementitious enough to bring about rapid hardening as well as early attainment of strength as a hydraulic binder of the resulting clay-based components containing it. Apart from the fact that particles 


\begin{tabular}{lcccc}
\hline \multicolumn{2}{c}{ Chemical constituents } & \multicolumn{2}{c}{ Proportion (\% wt) per material used } \\
Name & Formula & Clay soil & HCWPAN & Cement (PLC) \\
\hline Silicon dioxide (Silica) & $\mathrm{SiO}_{2}$ & 49.79 & 28.04 & 16.32 \\
Aluminium trioxide (Alumina) & $\mathrm{Al}_{2} \mathrm{O}_{3}$ & 30.68 & 1.61 & 3.62 \\
Ferric oxide & $\mathrm{Fe}_{2} \mathrm{O}_{3}$ & 6.90 & 1.05 & 2.81 \\
Calcium oxide (Lime) & $\mathrm{CaO}$ & 0.74 & 56.76 & 58.23 \\
Magnesium oxide & $\mathrm{MgO}$ & 0.21 & 1.30 & 0.91 \\
Sulphur trioxide & $\mathrm{SO}_{3}$ & - & 0.38 & 3.18 \\
Potassium oxide & $\mathrm{K}_{2} \mathrm{O}$ & 1.87 & 0.04 & - \\
Loss on ignition & $\mathrm{LOI}$ & 8.61 & 10.29 & 4.46 \\
\hline
\end{tabular}

TABLE 3. Chemical composition of the materials.

of HCWPAN are finer than those of cement, thus ensuring faster decomposition when heated, their values of loss on ignition indicate that the HCWPAN contains more compounds that decompose at high temperatures.

The results of experiments performed on the developed samples are presented in Table 4. In the case of water absorption, the replacement of clay with up to $10 \%$ of HCWPAN improves the waterresistive ability of the clay-based composites over the blank/control sample. This indicates that the lime, alumina, and silica in the HCWPAN react optimally at that level to enhance the inter-particle packing and micro-aggregation, thereby reducing the inter-particle voids and decreases the water uptake of the resulting composites. Beyond the $10 \%$ level of HCWPAN incorporation into the clay matrix, the water absorption of the composites increases. This may be due to the influence of numerous pores in the HCWPAN as a result of tininess of its particles. In addition, HCWPAN is the most porous in this case and its hydrophilicity is higher than that of the clay soil. Thus, an excess fraction of it in the resulting composite samples exercises a remarkable influence in promoting water absorption. It can, therefore, be posited that a no greater than $10 \%$ HCWPAN content is capable of improving the durability of the developed samples.

The use of cement as a stabilizing agent reduces water absorption at all levels considered in this study, though the water absorption obtained at a $20 \%$ content of the cement is greater than the value recorded at $15 \%$ level of loading. It is also observed that the reduction in the case of using HCWPAN up to $10 \%$ is more than when incorporating the cement at similar levels. This may be attributed to the fact that cement is made of Calcium silicates and aluminates and it has a high affinity for water. However, a one-way analysis of variance test yields a calculated F-value of 0.69 at $p<0.05$, thus revealing that the observed differences are not significant.

Whereas an increase in HCWPAN content creates more pores in the clay matrix, the pores are reduced when increasing the cement content. In other words, by increasing the cement content, the clay soil particles are covered with cement particles and bonding is enhanced among the particles, thereby making the resulting composite samples more solid in nature. This is possible because the hydrated component (such as calcium silicate hydrates) formed reduces the pore size (pore network) of the sample as the content of cement increases. The case with HCWPAN is different from this. Thus, since sorptivity is based on capillarity network, it increases steadily with increasing proportions of HCWPAN. This, plausibly, is due to the degree of fineness of HCWPAN which enables it penetrate the clay matrix significantly and create a network that promotes links for the enhancement of water infiltration. That is why, as sorptivity increases with the increasing HCWPAN content, a decrease is observed with the increasing proportion of cement.

There is no doubt that the variations in stabilizing mechanism of HCWPAN and cement can make the HCWPAN-modified clay soil and cement-modified clay soil differ in their properties. Samples with HCWPAN have a lower bulk density than their counterparts made with cement. At 5\%,10\%, $15 \%$, and $20 \%$ loading levels, the values obtained between the use of HCWPAN and incorporation of cement differ by $12.8 \%, 15.4 \%, 23.7 \%$, and $33.4 \%$ respectively. This may be attributed to the lightness of HCWPAN as compared to the clay soil. Also, the samples containing HCWPAN have a lower thermal conductivity than the ones containing cement fractions at similar loading levels. This is possible because HCWPAN is refractory and more porous than clay, even in the presence of water, whereas under such condition, cement produces more cohesive mortar than clay. Thus, with cement, a significant increase in inter-particle packing is ensured and that reduces air volume by minimizing pore spaces. On the contrary, though HCWPAN has finer particles as compared to the clay, its cohesiveness is lower, thereby leading to the increase in air space.

Figure 4 reveals that an increase in the content of HCWPAN causes a decrease in both the bulk density and thermal conductivity of the resulting clay composites, whereas cement increases them. Since the sam- 


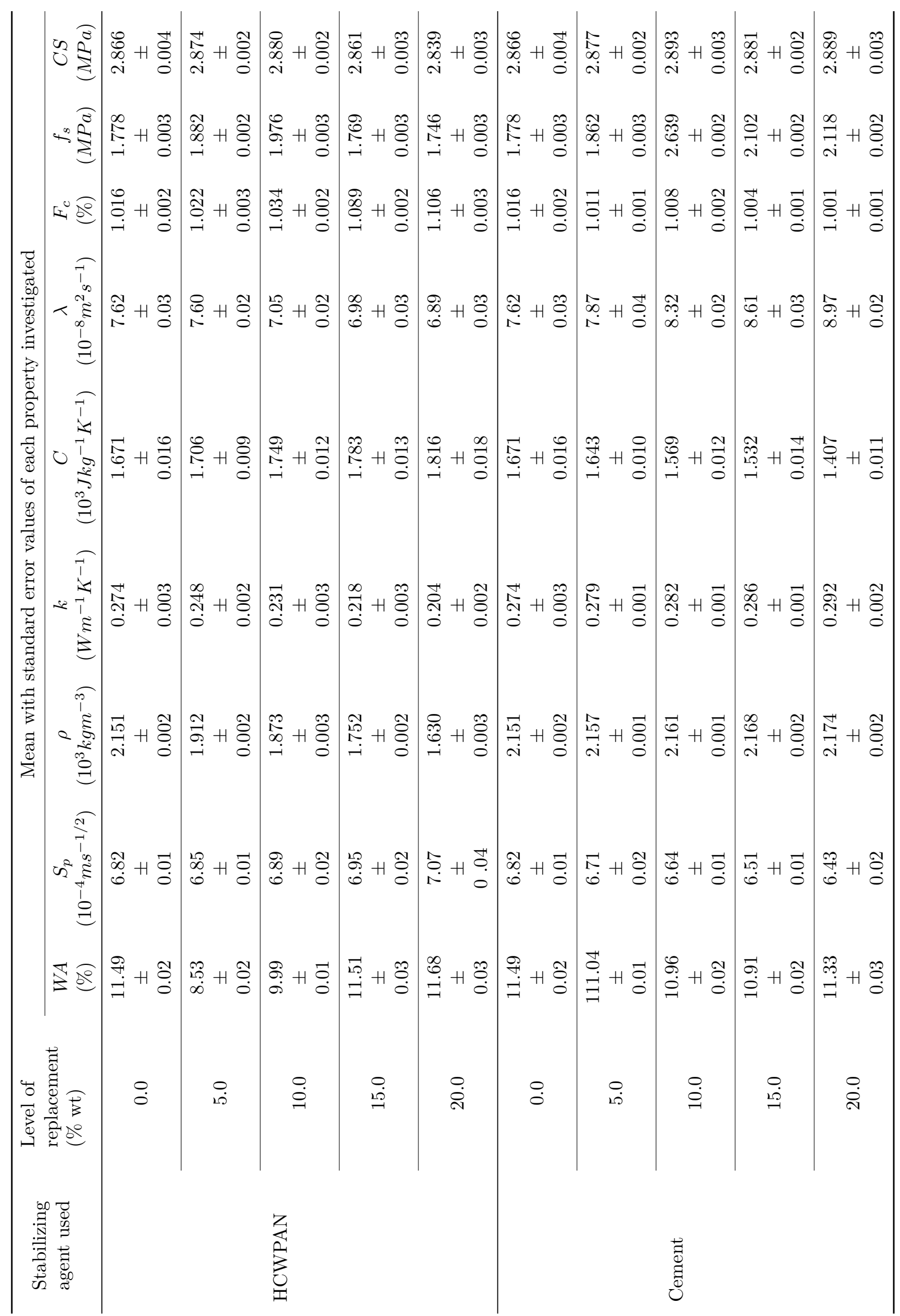

TABLE 4. Obtained results of the property tests performed on the developed samples. 


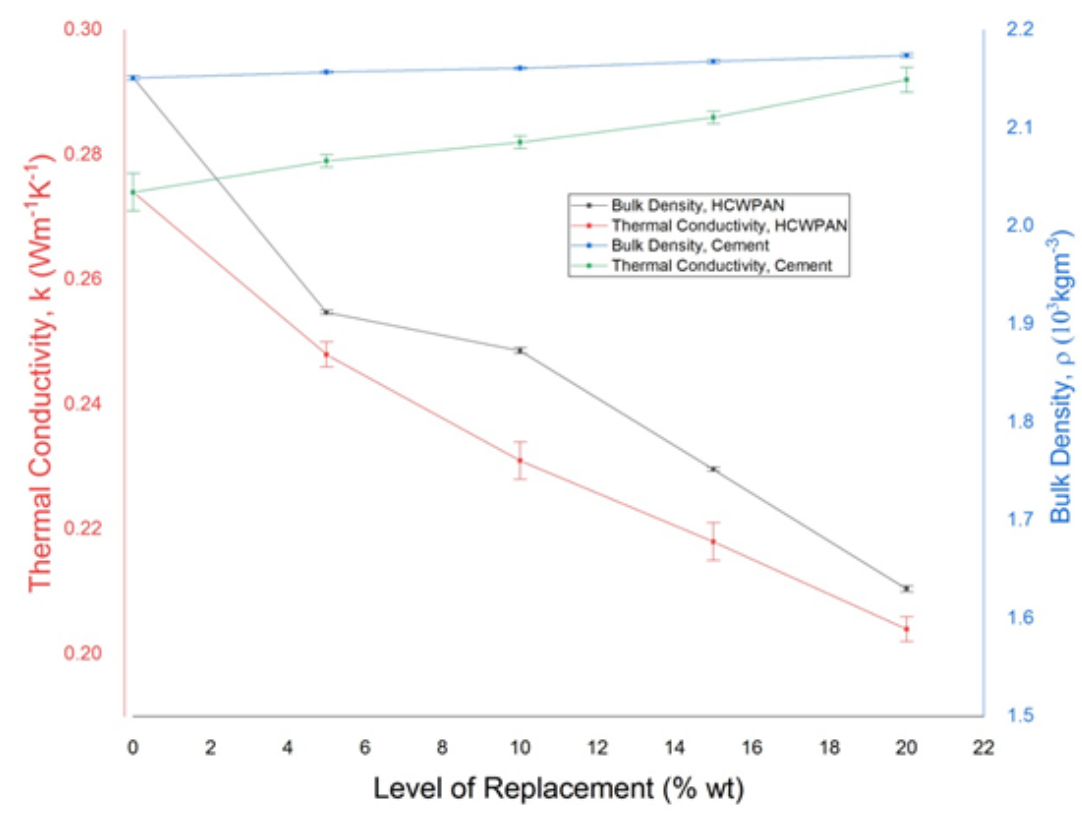

FiguRE 4. Variations of Bulk density and Thermal conductivity with proportions of the stabilizer.

ples are porous and also completely dry, this could be due to fact that as HCWPAN fraction increases, more interstices/pores exist, thus leading to the increase in air volume, whereas a drastic decrease in pore size and hence, the minimization of air volume is caused by the increasing content of cement. Consequently, bulk density of the developed composites decreases with the increase in HCWPAN, but increases with the incorporation of cement. The implication is that unlike in the case of cement, by increasing the proportion of HCWPAN, lightweight composites are produced. Solihu [56] and Srivastava et al. [57] in their research work observed similar effects on density when using cement for soil stabilization.

More so, it could be understood that air is a good thermal insulant (having thermal conductivity of about $0.025 \mathrm{Wm}^{-1} \mathrm{~K}^{-1}$ ) and it acts within the pores as heat transfer medium that controls and resists the flow of heat through the samples. Thus, an increase in HCWPAN loadings causes a decrease in the thermal conductivity because of the creation of more air-filled pores in the developed samples. Also, an increase in cement content brings about an increase in thermal conductivity, because of the improvement of packing behaviour, which reduces the air volume in the clay composites. In this case, it could be posited that thermal conductivity is a function of bulk density which is a function of porosity and as such, samples with HCWPAN content are more capable of ensuring a better thermal insulation performance than those made with cement at a similar content level. However, all the thermal conductivity values obtained for the studied samples fall within $0.023 \mathrm{Wm}^{-1} \mathrm{~K}^{-1}$ to $2.900 \mathrm{Wm}^{-1} \mathrm{~K}^{-1}$, which is the range recommended for heat-insulating and construction materials [58].
The results of the specific heat capacity test in this work substantiates the assertion that HCWPANmodified samples can exhibit a better thermal insulation performance than their counterparts with the cement content. As can be seen, the specific heat capacity increases with the increasing content of HCWPAN, but decreases as the fraction of cement increases. This simply implies that the incorporation of HCWPAN enhances the heat-storing ability of the developed composites, whereas the utilization of cement impedes such tendency. As such, for a unit temperature change, more energy will be required by a unit mass of the sample containing HCWPAN as compared to the case of using cement at a similar level to produce the sample. Alongside the thermal conductivity and bulk density (as expressed in eq. 4 in this study), the specific heat capacity influences the thermal diffusivity of the samples. Observably, thermal capacity (product of bulk density and specific heat capacity) shows a positive correlation with thermal conductivity in the case of samples with HCWPAN content, whereas a negative relationship is exhibited in the case of samples containing cement. Thus, with respect to proportion of the stabilizing agent utilized, the thermal diffusivity decreases with the increasing content of HCWPAN, but increases progressively with the increase in the percentage of cement. At $20 \%$ level of HCWPAN, the thermal diffusivity decreases by about $9.6 \%$, while it increases by $17.7 \%$ due to the utilization of cement up to a similar level. Thermal diffusivity may be regarded as a transport property that shows how a material undergoes temperature changes. Since a larger value of thermal diffusivity implies a faster rate of heat diffusion through a material, the results obtained in this study indicate that the temperature propagation is slower in HCWPAN- 


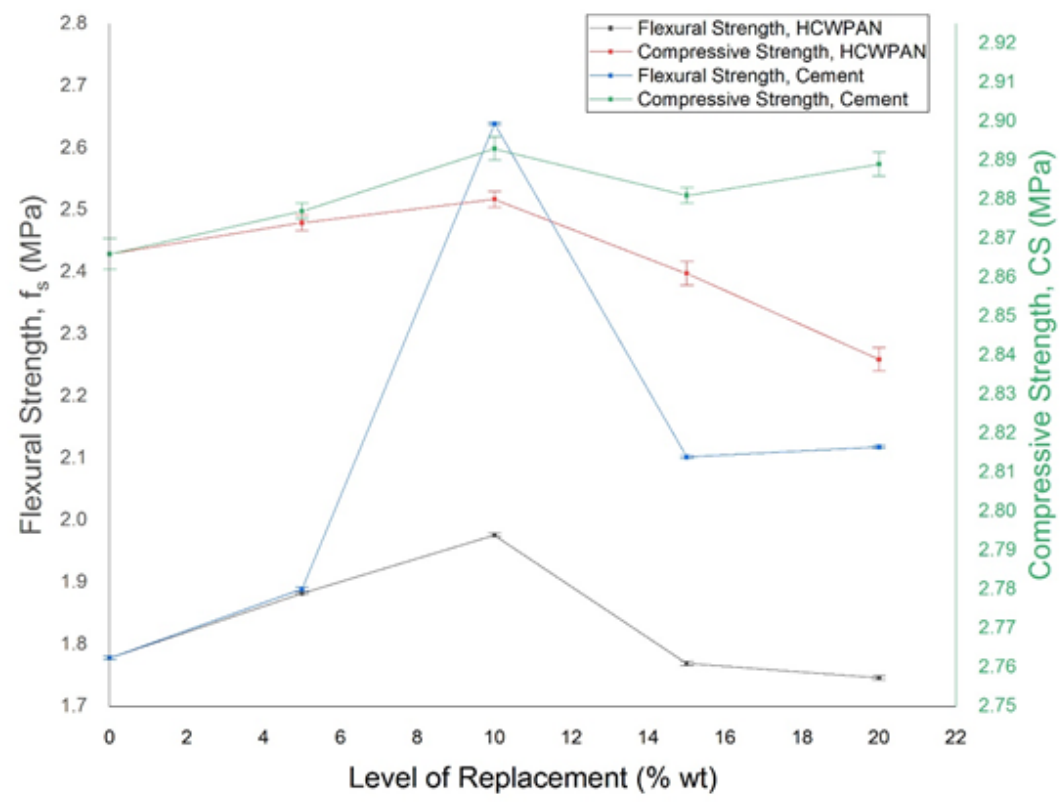

Figure 5. Variations of Flexural strength and Compressive strength with proportions of the stabilizer.

modified samples than in the case of those modified with cement even at similar content levels. This further substantiates that HCWPAN is more effective than cement in improving the thermal insulation efficiency of the clay soil for building purposes.

The extent to which a material is cohesive exercises a great deal of influence on the bonding strength of the material which, in turn, characterizes how strongly or weakly particles are held together in the material. Between the stabilizing agents used in this work, cement exhibits a greater cohesivity than HCWPAN in the presence of water. This possibly contributes to the greater flaking concentration observed in the case of samples containing HCWPAN, as compared to their counterparts with cement content. It is noticed that a sample made with up to $5 \%$ of cement content is as flaky as the control one, thus portraying that more than such a proportion of cement is needed to reduce the flakiness of the developed composite. Also observed is the fact that while the samples become flakier as HCWPAN fraction in them increases, their flaking concentration is lesser by increasing the proportions of cement. The implication in this case is that, at similar levels of usage, samples with the cement content are less susceptible to a mechanical wear than those fabricated with the HCWPAN fraction.

In the cases of flexural strength and compressive strength, the values obtained for using cement as a stabilizing agent are greater as compared to the results for the use of HCWPAN in modifying the clay soil. As a matter of fact, cement is mainly composed of lime and silica, which react with each other and other components in the mix when water is added. This reaction forms a combination of Tri-calcium silicate and Di-calcium silicate, which are referred to as $\mathrm{C}_{3} \mathrm{~S}$ and $\mathrm{C}_{2} \mathrm{~S}$ in the cement literature. Such mineral phases play a critical role in the chemical reaction and eventually generate a matrix of interlocking crystals that cover any inert filler and provide a high strength. The results simply reveal that samples developed with the cement content are stronger and stiffer than those produced similarly but with HCWPAN as a component. In other words, the modification of clay soil with cement yields clay-based composites with a greater ability to withstand rupture and shattering under loading situations as compared to those stabilized with HCWPAN. At 5\%,10\%,15\%, and $20 \%$ proportions, flexural strength of the studied samples differs by $0.3 \%, 33.6 \%, 18.8 \%$, and $21.3 \%$, respectively, while compressive strength differs by $0.1 \%, 0.5 \%, 0.7 \%$, and $1.8 \%$, respectively, between the use of HCWPAN and cement for the modification of the clay soil. Among other ways, the development of higher strength and stiffness is achieved by reducing voids, binding particles and aggregates together, and maintaining flocculation. Additionally, the $\mathrm{Ca}(\mathrm{OH})_{2}$ crystals generated by cement as by-product of the hydration of Calcium silicates are pure and fine, and as such, they are more reactive. This provides the calcium necessary for the ion exchange during the physicochemical reaction between the cement and clay soil.

The illustration in Figure 5 depicts the flexural strength and compressive strength trend with the proportions of the stabilizers used. It can be observed that the strength increases up to the $10 \%$ incorporation level, beyond which they decline in both cases. This signifies that $10 \%$ is the optimum level for achieving the maximum strength. Beyond this level, a sharp decline is revealed. As for the HCWPAN, this may be because the silica content can react optimally only when at most $10 \%$ of the stabilizing agent is utilized. That is to say, if a subsequent increase in its propor- 


\begin{tabular}{lcccccc}
\hline $\begin{array}{l}\text { Equipment } \\
\text { applied }\end{array}$ & $\begin{array}{c}\text { Nominal } \\
\text { power rating } \\
(\mathrm{W})\end{array}$ & Energy source & Application & $\begin{array}{c}\text { Duration } \\
\text { (Hours) }\end{array}$ & $\begin{array}{c}\text { Energy } \\
\text { consumed } \\
(\mathrm{GJ})\end{array}$ & $\begin{array}{c}\text { Quantity of the } \\
\text { material } \\
\text { processed (ton) }\end{array}$ \\
\hline Incinerator & - & - & Paper ashing & 1 & - & \\
Autoclave & 3120 & Electricity & Heat treatment & 12 & 0.135 & 0.134 \\
Furnace & 1800 & Electricity & Calcinations & 4 & 0.026 & \\
Ball miller & 3100 & Electricity & Ball milling & 6 & 0.067 & \\
\hline
\end{tabular}

TABLE 5. Analysis of energy consumption during HCWPAN preparation.

tion is introduced into the clay matrix, the excess of it (the HCWPAN) may not have the opportunity to be utilized, thus resulting in increased void fractions and pores that weaken the inter-particle bonding in the developed composites. With the use of cement as a stabilizing agent, the maximum strength values are obtained at similar loading levels showing that a further increment in the cement fraction may not necessarily lead to increased strength, but impairment of the expected performance as noted by Mahedi et al. [59. Notably, all the studied samples have a compressive strength value that compares favorably with $2.9 \mathrm{MPa}$, reported 60] for cement-stabilized clay soil containing $10 \%$ by volume of cement and cured for 28 days. Also, the studied samples possess a compressive strength that meets the minimum requirement stipulated to be 2.5 MPa for non-load bearing walling elements.

Table 5 shows the analysis of the energy consumed during the HCWPAN preparation in the study. It can be inferred from the data presented that the total energy consumption is 0.228 GJ for processing 0.134 tons of the material. This means that, on average, the consumption is $1.701 \mathrm{GJ}$ per ton. In the case of the cement production, approximately 3.2 to $6.3 \mathrm{GJ}$ amount of energy is needed and about 1.7 tons of raw material (mainly limestone) per ton of the clinker are generated 61. In other words, energy consumption is 1.882 to 3.706 GJ per ton of cement. Comparatively, it can be deduced that the processes involved in preparing a ton of HCWPAN is about $9.6 \%$ to $54.1 \%$ more energy-saving than those used for cement manufacturing.

\section{Conclusion}

The following conclusions were drawn based on the results of the investigation carried out in this study:

- The ranking of oxides proportions in HCWPAN is similar to that of the Portland Limestone Cement utilized in this study.

- Replacement of clay matrix with up to $20 \%$ of HCWPAN caused a decrease in bulk density, thermal conductivity, and thermal diffusivity by $24.2 \%$, $25.5 \%$, and $9,6 \%$, respectively, whereas with the use of the cement, increments of $1.1 \%, 6.6 \%$, and $17.7 \%$ respectively, were observed.
- Compared with the case of the cement used in this work, the preparation of a kilogram of HCWPAN is more energy-saving and the clay-based composites developed with it are capable of ensuring a better thermal comfort as building materials, especially in tropical zones.

- At $10 \%$ content level of either stabilizing agent, the fabricated composites possessed the maximum flexural strength and compressive strength, though with a variation of about $33.6 \%$ and $0.5 \%$, respectively, for the use of the cement over HCWPAN.

- Since waste papers are cheaply and constantly available in large quantities, the use of HCWPAN to modify clay soil for building purposes could serve as a promising way of managing the waste while ensuring a sustainable building construction.

- The cement and HCWPAN have comparable influences on the durability behaviour, such as water absorption and sorptivity of the modified clay samples, thus signifying that HCWPAN could be utilized as an alternative stabilizer to cement for the modification of clay soil for building purposes.

- Valorisation of waste papers, as described in this study, can serve as a safe disposal technique of the waste while improving the economy of the building sector.

\section{REFERENCES}

[1] J. Bredenoord. Sustainable building materials for low-cost housing and the challenges facing their technological developments: Examples and lessons regarding bamboo, earth-block technologies, building blocks recycled materials, and improved concrete panels. Journal of Architectural Engineering Technology 6:187, 2017. https://doi.org/10.4172/2168-9717.1000187

[2] E. Tsega, A. Mosisa, F. Fuga. Effects of firing time and temperature on physical properties of fired clay bricks. American Journal of Civil Engineering 5(1):21-26, 2017. https://doi.org/10.11648/j.ajce.20170501.14.

[3] S. Karaman, H. Gunal, S. Ersahin. Assessment of clay bricks compressive strength using quantitative values of colour components. Construction and Building

Materials 20(5):348-354, 2006. https:

//doi.org/10.1016/j.conbuildmat.2004.11.003.

[4] H. T. Rondonane, J. A. Mbeny, E. C. Bayiga, P. D. Ndjigui. Characterization and application tests of kaolinite clays from Aboudeia (southeastern Chad) in 
fired bricks making. Scientific African 7:e00294, 2020. https://doi.org/10.1016/j.sciaf.2020.e00294

[5] E. Garzón, M. Cano, B. C. O’Kelly, P. J.

Sánchez-Soto. Phyllite clay-cement composites having improved engineering properties and material applications. Applied Clay Sciences 114:229-233, 2015. https://doi.org/10.1016/j.clay.2015.06.006

[6] M. S. El-Mahllawy, A. M. Kandeel. Engineering and mineralogical characteristics of stabilisedunfired montmorrillonite clay bricks. HBRC Journal 10(1):82-91, 2014. https://doi.org/10.1016/j.hbrcj.2013.08.009

[7] L. M. A. Santos, J. A. S. Neto, A. F. N. Azerêdo. Soil characterisation for adobe mixtures containing Portland cement as stabiliser. Matéria 25(1):1-10, 2020. https://doi.org/10.1590/S1517-707620200001.0890.

[8] C. Chen, G. Habert, Y. Bouzidi, A. Jullien. Environmental impact of cement production: detail of the different processes and cement plant variability evaluation. Journal of Cleaner Production 18(5):478-485, 2010. https://doi.org/10.1016/j.jclepro.2009.12.014

[9] S. Zhang, E. Worrell, W. Crijns-Graus. Evaluating co-benefits of energy efficiency and air pollution abatement in China's cement industry. Applied Energy 147:192-213, 2015. https://doi.org/10.1016/j.apenergy.2015.02.081

[10] W. Shen, L. Cao, Q. Li, et al. Quantifying $\mathrm{CO}_{2}$ emissions from China's cement industry. Renewable and Sustainable Energy Reviews 50:1004-1012, 2015. https://doi.org/10.1016/j.rser.2015.05.031

[11] K. S. Reddy, P. S. Vivek, K. S. Chambrelin. Stabilization of expansive soil using bagasse ash. International Journal of Civil Engineering and Technology 8(4):1730-1736, 2017.

[12] K. C. P. Faria, R. F. Gurgel, J. N. F. Holanda. Recycling of sugarcane bagasse ash waste in the production of clay bricks. Journal of Environmental Management 101:7-12, 2012. https://doi.org/10.1016/j.jenvman.2012.01.032

[13] S. Zahan, S. Akter, R. Ahsan. Effects of rice husk in clay bricks. In 5th International Conference on Civil Engineering for Sustainable Development. Khulna, Bangladesh.

[14] O. Agbede, M. Joel. Effcet of rice husk ash (RHA) on the properties of ibaji burnt clay bricks. American Journal of Scientific and Industrial Research 2(4):674-677, 2011. https://doi.org/10.5251/ajsir.2011.2.4.674.677

[15] Y. C. Khoo, I. Johari, Z. A. Ahmad. Influence of rice husk ash on the engineering properties of fired-clay brick. Advanced Materials Research 795:14-18, 2013. https:// doi.org/10.4028/www.scientific.net/AMR.795.14

[16] V. S. Sankar, P. D. A. Raj, S. J. Raman. Stabilization of expansive soil by using agricultural waste. International Journal of Engineering and Advanced Technology 8(3S):154-157, 2019. https://www.ijeat.org/wp-content/uploads/ papers/v8i3S/C10310283S19.pdf
[17] S. S. Shinde, G. K. Patil. Study on utilization of agricultural waste as soil stabilizer. International Journal of Latest Trends in Engineering and Technology 7(1):227230, 2016. https://doi.org/10.21172/1.71.032.

[18] O. D. Afolayan, O. M. Olofinade, I. I. Akinwumi. Use of some agricultural wastes to modify the engineering properties of subgrade soils: A review. Journal of Physics: Conference Series 1378:022050, 2019. https://doi.org/10.1088/1742-6596/1378/2/022050

[19] S. Mandal, J. P. Singh. Stabilization of soil using ground granulated blast furnace slag and fly ash. International Journal of Innovative Research in Science, Engineering and Technology 5(12):21121-21126, 2016.

[20] J. Dayalan. Comparative study on stabilization of soil with ground granulated blast furnace slag (GGBS) and fly ash. International Research Journal of Engineering and Technology 3(5):2198-2204, 2016. https://www. irjet.net/archives/V3/i5/IRJET-V3I5465.pdf

[21] L. Yadu, R. K. Tripathi. Effects of granulated blast furnace slag in the engineering behavior of stabilized soft soil. Procedia Engineering 51:125-131, 2013. https://doi.org/10.1016/j.proeng.2013.01.019

[22] B. D. Nath, M. K. A. Molla, G. Sarkar. Study on strength behavior of organic soil stabilized with fly ash. International Scholarly Research Notices 2107:5786541, 2107. https://doi.org/10.1155/2017/5786541

[23] H. Singh, G. S. Brar, G. S. Mudahar. Evaluation of characteristics of fly ash-reinforced clay bricks as building materials. Journal of Building Physics 40(6):530-543, 2017. https://doi.org/10.1177/1744259116659662.

[24] F. Changizi, A. Haddad. Strength properties of soft clay treated with mixture of nano-sio 2 and recycled polyester fiber. Journal of Rock Mechanics and Geotechnical Engineering 7(4):367-378, 2015. https://doi.org/10.1016/j.jrmge.2015.03.013

[25] S. G. Jahromi, H. Zahedi. Investigating the effecting of nano aluminum on mechanical and volumetric properties of clay. Amirkabir Journal of Civil Engineering 50(3):597-606, 2018. https://doi.org/10.22060/ceej.2017.12241.5157.

[26] F. Changizi, A. Haddad. Improving the geotechnical properties of soft clay with nano-silica particles. Proceedings of the Institution of Civil Engineers Ground Improvement 170(2):62-71, 2018. https://doi.org/10.1680/jgrim.15.00026.

[27] N. Ghasahkolaei, A. Janalizadeh, M. Jahanshahi, et al. Physical and geotechnical properties of cement-treated clayey soil using silica nanoparticles: an experimental study. The European Physical Journal Plus 131:134, 2016. https://doi.org/10.1140/epjp/i2016-16134-3

[28] Z. H. Majed, M. R. Taha. Effect of nanomaterial treatment on geotechnical properties of a penang soil. Asian Journal of Scientific Research 2(11):587-592, 2012.

[29] M. O'mara. How much paper is used in one day? Record Nations, Last updated: January 3, 2020, https://www.recordnations.com/

[30] R. W. J. McKinney. Technology of paper recycling. Blackie-Academic and Professional, Chapman and Hall, New York, 1995. 
[31] O. P. Folorunso, B. U. Anyata. Potential use of waste paper/sludge as a ceiling board material. Advanced Materials Research 18-19:49-53, 2007. https://doi. org/10.4028/www.scientific.net/AMR .18-19.49

[32] U. W. Robert, S. E. Etuk, G. P. Umoren, O. E. Agbasi. Assessment of thermal and mechanical properties of composite board produced from coconut (cocos nucifera) husks, waste newspapers and cassava starch. International Journal of Thermophysics 40(9):83, 2019. https://doi.org/10.1007/s10765-019-2547-8

[33] P. S. E. Ang, A. H. I. Ibrahim, M. S. Abdullah. Preliminary study of ceiling board from composite material of rice husk, rice husk ash and waste paper. Progress in Engineering Application and Technology 1(1):104-115, 2020. https://publisher.uthm.edu.my/ periodicals/index.php/peat/article/view/241.

[34] E. U. Nathaniel, U. W. Robert, M. E. Asuquo. Evaluation of properties of composite panels fabricated from waste newspaper and wood dust for structural application. Journal of Energy Research and Reviews $\mathbf{5}(1): 8-15,2020$. https://doi.org/10.9734/JENRR/2020/v5i130138

[35] U. W. Robert, S. E. Etuk, O. E. Agbasi, et al. Investigation of thermal and strength properties of composite panels fabricated with plaster of Paris for insulation in buildings. International Journal of Thermophysics 42(2):25, 2021. https://doi.org/10.1007/s10765-020-02780-y

[36] S. O. Amiandamhen, S. O. Osadolor. Recycled waste paper-cement composite panels reinforced with kenaf fibres: durability and mechanical properties. Journal of Material Cycles and Waste Management 22:1492-1500, 2020. https://doi.org/10.1007/s10163-020-01041-2

[37] J. P. Azar, M. Najarchi, B. Sanaati, et al. The experimental assessment of the effect of paper waste ash and silica fume on improvement of concrete behaviour. KSCE Journal of Civil Engineering 23:4503-4515, 2019. https://doi.org/10.1007/s12205-019-0678-x

[38] B. M. Kejela. Waste paper ash as partial replacement of cement in concrete. American Journal of Construction and Building Materials 4(1):8-13, 2020. https://doi.org/10.11648/j.ajcbm.20200401.12.

[39] H. M. B. Al-Hashemi, O. S. B. Al-Amoudi. A review on the angle of repose of granular materials. Powder Technology 330:397-417, 2018. https://doi.org/10.1016/j.powtec.2018.02.003.

[40] ASTM D7928, Standard test method for particle-size distribution (gradation) of fine-grained soils using the sedimentation (hydrometer) analysis. ASTM International, West Conshohocken, 2017.

[41] M. Bediako, E. O. Amankwah. Analysis of chemical composition of cement in Ghana: A key to understand the behavoiur of cement. Advances in Materials Science and Engineering 2015:2015, 2015. https://doi.org/10.1155/2015/349401.

[42] A. I. Inegbenebor, A. O. Inegbenebor, R. C. Mordi, et al. Determination of the chemical compositions of clay deposits from some part of South West Nigeria for industrial applications. International Journal of Applied Sciences and Biotechnology 4(1):21-26, 2016. https://doi.org/10.3126/ijasbt.v4i1.14214.

[43] U. W. Robert, S. E. Etuk, O. E. Agbasi, U. S. Okorie. Quick determination of thermal conductivity of thermal insulators using a modified Lee-Charlton's disc apparatus technique. International Journal of Thermophysics 42(8):113, 2021. https://doi.org/10.1007/s10765-021-02864-3

[44] S. Shrestha. A case study of brick properties manufactured in Bhaktapur. Journal of Science and Engineering 7:27-33, 2019. https://doi.org/10.3126/jsce.v7i0.26786

[45] U. W. Robert, S. E. Etuk, O. E. Agbasi. Bulk volume determination by modified water displacement method. Iraqi Journal of Science 60(8):1704-1710, 2019. https://doi.org/10.24996/ijs.2019.60.8.7.

[46] U. W. Robert, S. E. Etuk, O. E. Agbasi, et al. On the hygrothermal properties of sandcrete blocks produced with sawdust as partial replacement of sand. Journal of the Mechanical Behavior of Materials 30(1):144-155, 2021. https://doi.org/10.1515/jmbm-2021-0015

[47] D. R. Lide. CRC Handbook of Chemistry and Physics. 85th ed. CRC Press, Boca Raton, 2005.

[48] S. E. Etuk, U. W. Robert, O. E. Agbasi. Design and performance evaluation of a device for determination of specific heat capacity of thermal insulators. Beni-Suef University Journal of Basic and Applied Sciences $\mathbf{9}(1): 34,2020$.

https://doi.org/10.1186/s43088-020-00062-y

[49] ASTM D790, Standard test methods for flexural properties of unreinforced and reinforced plastics and electrical insulating materials. ASTM International, West Conshohocken, 2017.

[50] U. W. Robert, S. E. Etuk, O. E. Agbasi, S. A. Ekong. Properties of sandcrete block produced with coconut husk as partial replacement of sand. Journal of Building Materials and Structures 7:95-104, 2020. https://doi.org/10.5281/zenodo.3993274.

[51] H. Lu, X. Guo, Y. Liu, X. Gong. Effects of particle size on flow mode and flow characteristics of pulverised coal. KONA Powder and Particle Journal 32:143-153, 2015. https://doi.org/10.14356/kona.2015002

[52] X. Guiling, C. Xiaoping, L. Cai, et al. Experimental investigation on the flowability properties of cohesive carbonaceous powders. Journal of Particulate Science and Technology 35(3):322-329, 2016. https://doi.org/10.1080/02726351.2016.1154910

[53] USP, powder flow. In The United States Pharmacopeia 30-National Formulary 25 Convention. Rockville, 2007.

[54] P. M. Velasco, M. P. M. Ortíz, M. A. M. Giró, L. M. Velasco. Fired clay bricks manufactured by adding wastes as sustainable construction material - a review. Construction and Building Materials 63:97-107, 2014. https://doi.org/10.1016/j.conbuildmat.2014.03.045

[55] ASTM C618, Standard specification for coal fly ash and raw or calcined natural pozzolan for use in concrete. ASTM International, West Conshohocken, 2019. 
[56] H. Solihu. Cement soil stabilization as an improvement technique for soil track subgrade, and highway subbase and base courses: A review. Journal of Civil and Environmental Engineering 10(3):1-6, 2020. https://doi.org/10.37421/jcde.2020.10.344.

[57] S. Srivastava, J. Yadav, R. Pandey. Analysis of stabilization of soil cement for base of railway track \& subgrade. International Journal of Engineering Development and Research 6(1):263-265, 2018.

[58] E. R. E. Rajput. Heat and Mass Transfer. 6th Revised ed. S. Chand \& Company PVT Ltd, New Delhi, 2015.

[59] M. Mahedi, B. Cetin, D. J. White. Performance evaluation of cement and slag stabilized expansive soils.
Transportation Research Record: Journal of the Transportation Research Board 2672(52):164-173, 2018. https://doi.org/10.1177/0361198118757439

[60] M. G. Hiwot, E. T. Quezon, G. Kebede. Comparative study on compressive strength of locally produced fired clay bricks and stabilized clay bricks with cement and lime. Global Scientific Journal 5(12):147-157, 2017.

[61] A. Rahman, M. G. Rasul, M. M. K. Khan, S. Sharma. Recent development on the uses of alternative fuels in cement manufacturing process. Fuel 145:84-99, 2015. https://doi.org/10.1016/j.fuel.2014.12.029 